\title{
Pharmacogenetics of Cancer and DNA Repair Enzymes
}

\author{
Tahar van der Straaten ${ }^{1}$, Leon Mullenders ${ }^{2}$ and Henk-Jan Guchelaar ${ }^{1}$ \\ ${ }^{1}$ Department of Clinical Pharmacy \& Toxicology \\ ${ }^{2}$ Department of Toxicogenetics, Leiden University Medical Center \\ The Netherlands
}

\section{Introduction}

Pharmacogenetics is focused on finding associations between drug response and the genetic background of a patient. ${ }^{38}$ Resequencing of the human genome revealed that nucleotide variation between individuals exists in $0.1 \%$ of the genome, which corresponds to 3 million differences. These variations occur in more than $1 \%$ of a population and are designated as single nucleotide polymorphisms (SNP), normally not causing any disease. Functional variants caused by SNPs in drug related genes (such as metabolism enzymes, transporters and receptors) have become of interest more and more in recent years.21,22,40,73 Variations that occur less frequent than $1 \%$ are designated as mutations and could be disease causing. Pharmacogenetic research has been expanded dramatically, with 1334 publications in the past century starting from 1961, while 7654 papers have been published since the year 2000 (pubmed accession date: November 18, 2010). The ultimate goal of pharmacogenetic research is the establishment of personalized medicine, aiming in prescribing the best choice of drug with the optimal concentration. ${ }^{67}$ Even the route of administration could be considered. At present, pharmacogenetics is not applied widely in clinical practice as a diagnostic tool, but is mainly restricted to research, which is, finding associations between drug response and genetic background within a group of patients. Much research is being performed in order to achieve a more beneficial cancer therapy, although pharmacogenetic research is also active in other fields like rheumatoid arthritis, ,42,52 transplantation ${ }^{50,84}$ and diabetes. ${ }^{19,51}$

The application of whole genome techniques for predicting patients' sensitivity or resistance to a drug is the definition of pharmacogenomics. ${ }^{27,68}$

At present, most pharmacogenetic research is focused on enzymes that control the metabolism and uptake of many clinically used drugs. Most of these drugs are metabolized by Cytochrome $\mathrm{P} 450$ of which variant alleles are common that affects drug effectiveness.15,24,33 Roche diagnostics has developed an array to screen for the most important SNPs in Cytochrome P450 isoenzyme 2D6.72 This array is the first one that is approved by FDA for diagnostic testing. Other interesting genes with relatively high frequency of variant alleles are transporters such as MDR1.5,41,70 Affymetrix had developed an array (DMET) to screen for 1936 SNPs in genes that are involved in drug metabolism, uptake and detoxification. ${ }^{16}$ 
Although screening for SNPs in DNA mismatch repair enzymes is a standard method for diagnosis of hereditary nonpolyposis colorectal cancer (HNPCC), ${ }^{45,61}$ pharmacogenetics of DNA repair enzymes is only applied in research settings and is discussed later in this chapter.

\section{Genetic characteristics of tumor cells}

When a normal cell loses the ability to regulate its own cell division but instead continuously divides, then this cell has become a tumor cell (reviewed by Hanahan and Weinberg ${ }^{25}$ ). Benign tumors result from minor imbalances in tissue whereby too many genetically stable cells are produced. These cells grow expansively and since they are often encapsulated, they can be removed by surgery. Since blood cells travel throughout the body, clonal expansion of these cells never result in benign tumors, but always in malignant tumors. Malignant tumors are genetically instable, metastasize easily and are causing cancer. These type of tumors can only be removed by surgery if they are caught in early development, but many solid tumors smaller than $1 \mathrm{~cm}$ have already been metastasized. Due to their genetic instability, tumor cells have different genetic characteristics and consequently a heterogeneous phenotype. In such a heterogeneous population, the cells that are best adapted to their environment survive better than the less malignant ones. Genetic alterations consist of "loss of heterozygosity", translocations, mutations and disturbance in methylation.

\section{Platinum drugs for cancer treatment}

The treatment of cancer depends fully on the type of tumor and often several approaches are made to kill the tumor. Antibodies are frequently used to block receptors that are over expressed in the tumor, or to scavenge growth stimulating factors. For example the epidermal growth factor receptor (EGFR) is essential for normal cellular function, however, increased levels of EGFR mRNA are associated with metastasis and aggressive tumor growth. ${ }^{39}$ EGFR is over expressed in tumor cells and many therapies are focused on blocking this receptor using antibodies such as cetuximab or panitumumab. 39,56,63 On the other hand, platinum-drugs intercalate in the tumor DNA thereby inhibiting DNA replication and thus inducing cell death. 8,9 Platinum containing drugs such as cisplatin, carboplatin or oxaliplatin, have a broad range of activity in malignant disease and are used to threat many types of cancer. In general, the antitumor effect of platinum drugs is the result of intercalation of platinum in the DNA helix, causing the formation of platinumDNA cross-links which ultimately leads to programmed cell death.

Cisplatin was the first platinum drug approved for the treatment of both ovarian and testicular cancer in $1978 .{ }^{29}$ At present, more than $80 \%$ of patients with testicular cancer can be cured with cisplatin-based chemotherapy. ${ }^{31}$ It was also applied to threat other solid tumors such as cervical, head and neck, lung and bladder cancer. Unfortunately, neither of these cancer types could be treated with a similar efficiency as accounts for testicular cancer. ${ }^{64}$ Cisplatin was the most commonly used chemotherapy drug but its use is limited by severe side effects such as gastrointestinal and renal toxicities. For that reason, an analogue with less toxicity was developed that replaced cisplatin in many chemotherapeutic regiments. This second-generation platinum drug was carboplatin which has equivalent 
activity, is more stable, and is less toxic than cisplatin. Especially neurotoxicity is less frequently observed when compared with cisplatin. ${ }^{26}$ Additionally, loss of hearing is less frequently observed in carboplatin-treated patients than is seen in patients treated with cisplatin. ${ }^{10,83}$ Carboplatin has a different spectrum of toxicity, as its primary toxic effects are heamatological.78 A third generation-platinum compound was oxaliplatin. Oxaliplatin shows no cross resistance with cisplatin and carboplatin which is an important benefit for the treatment of colorectal cancer. Colorectal cancer appeared extremely insensitive to cisplatin and carboplatin. Another advantage is the toxicity profile which is much less frequent, although neurotoxicity is still observed. ${ }^{26}$

Cisplatin and carboplatin, that share the same mechanism of action, are fully cross resistant and form identical lesions in DNA. The mechanism of action of oxaliplatin is different and oxaliplatin does not share cross resistance. ${ }^{17,44}$

\section{Platinum induced DNA damage}

As mentioned above, the cytotoxic property of platinum $(\mathrm{Pt})$-drugs is the intercalation in cellular DNA, forming Pt-adducts, that consequently inhibit DNA replication and thus induce cell death. ${ }^{9}$ Although Pt-based drugs are the most widely used in cancer treatment, many tumors are completely resistant to these drugs. The difference in clinical response is thought to be due, in part, to the pharmacokinetics of these drugs, as summarized by Marsh et al. ${ }^{53}$ Once Pt is inside the cell, Pt-adducts are formed within the DNA and a cellular defense is activated (Figure 1). DNA is the preferential and cytotoxic target for platinating agents. Three different types of lesions can be formed: monoadducts, intrastrand crosslinks and interstrand crosslinks (Figure 2). Monoadducts are first formed, but almost all monoadducts then react to form crosslinks of which the majority is intrastrand crosslinks. Cisplatin- and carboplatin-induced crosslinks bend the DNA double helix by $32-35^{\circ}$ toward the major groove, whereas oxaliplatin induced crosslinks bend the double helix even more. ${ }^{18}$

Oxaliplatin adducts are bulkier and more hydrophobic than those formed by cisplatin and carboplatin, leading to different effects in the cell.55,65 Interstrand crosslinks induce more steric changes in DNA and are therefore considered to be more toxic. Cisplatin and oxaliplatin have been found to form the same types of adducts at the same sites on the DNA. 35,58 Both cisplatin and oxaliplatin form approximately $60-65 \%$ intrastrand GG, $25-30 \%$ intrastrand AG, 5-10\% intrastrand GNG, and 1-3\% interstrand GG diadducts. 20

\section{DNA repair mechanisms}

Platinum adducts are recognized by the cellular DNA repair system and resistance to platinum chemotherapy is achieved by activity of either the nucleotide excision repair (NER), mismatch repair (MMR) or homologous recombination (HR) pathways. On the other hand, mutations in key enzymes of these pathways result in sensitivity to platinum drugs. The nucleotide excision repair system deals with helix-distorting lesions that interfere with base pairing and obstruct transcription and normal replication. Therefore, NER is the most important pathway involved in the efficacy of platinum chemotherapeutic therapy. ${ }^{64}$ NER consists of two sub-pathways, global genome NER (GG-NER) that screens the entire genome for damage, and transcription coupled repair (TCR) that screens for lesions that might block elongating RNA polymerases. ${ }^{76}$ Specific protein complexes are involved in the 


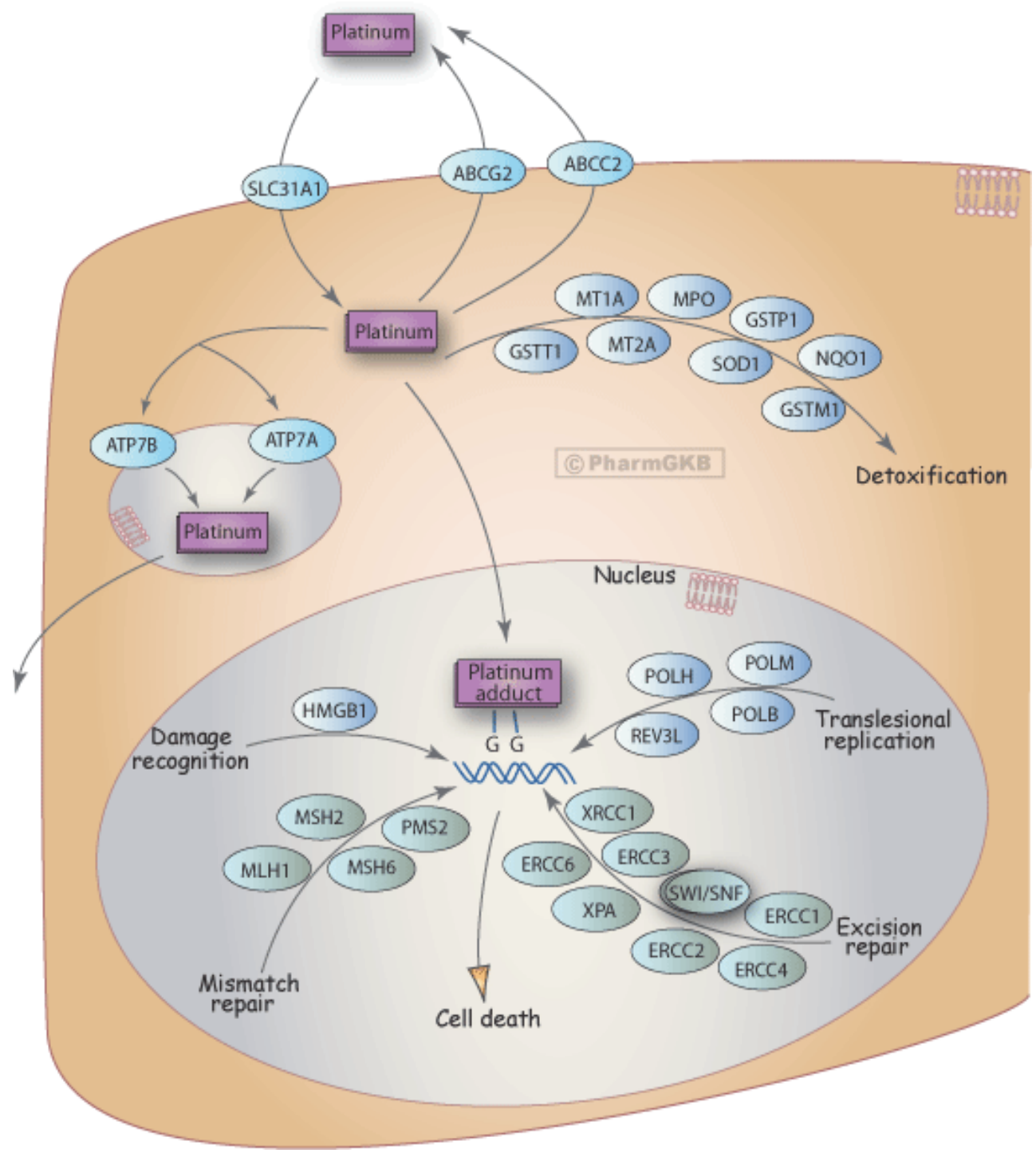

Fig. 1. Cellular response to platinum exposure. Figure taken from http:/ / www.pharmgkb.org/do/serve?objId=PA150642262\&objCls=Pathway. XPC, sensor for DNA damage, has not been depicted in this figure. 


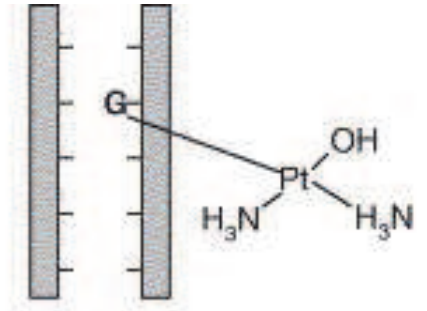

DNA Monoadduct

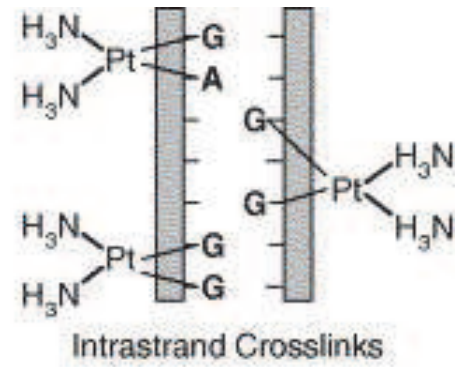

Intrastrand Crosslinks

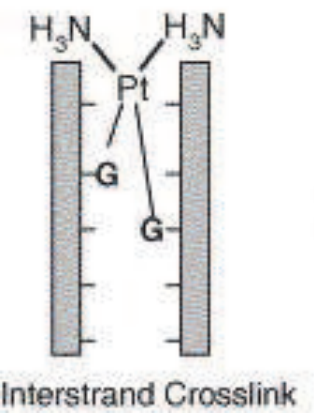

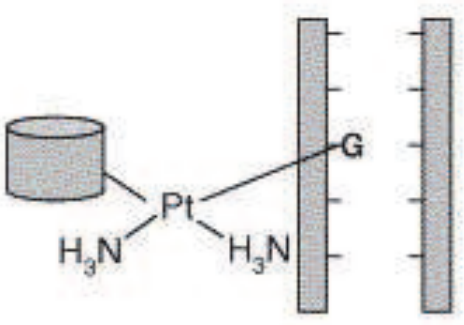

DNA-Protein Crosslink

Fig. 2. Platinating agent adducts on DNA. Platinating agents are able to react with DNA to form monoadducts, intrastrand crosslinks, interstrand crosslinks and DNA-protein crosslinks. Figure taken from Rabik and Dolan. ${ }^{64}$

first step of DNA damage recognition of GG-NER and TC-NER. Nomenclature of key enzymes involved in NER is listed in table 1. In GG-NER, XPC-hHR24B screens first on the basis of disrupted base pairing instead of lesions, 75 explaining why mildly distorted damage is poorly repaired. ${ }^{75}$ In TCR, two specific enzymes are necessary to displace the stalled polymerase to make the lesion accessible for repair, CSA and CSB. ${ }^{46}$ Next steps in the NER system are identical (Figure 3). In general, the helix structure of about 30 base pairs around the damaged site, is opened by helicase XPD (part of the transcription factor TFIIH). Replication protein A binds to the undamaged site to stabilize the open DNA strands. Next, XPG and ERCC1/XPF cleave the DNA strand on both sides of the damaged site. The DNA replication machinery then completes the repair by filling the gap. In total, more than 25 proteins participate in NER and for almost all NER factors, mouse mutants have been generated ${ }^{14}$ some of which show features of premature ageing. In general, mutations in key enzymes of NER (such as XPD, XPB, XPG and ERCC1) compromise NER and cause developmental delay and affect transcription. ${ }^{80}$ The incidence of sun induced skin cancer is $>1000$ fold increased, whereas frequency of internal tumors is modestly elevated.

The presence of dinucleotide repeats in the human genome is quite common and form unstable motifs in some cancers. ${ }^{36}$ This phenotype of microsatellite instability is caused by defects in MMR in the hereditary nonpolyposis colorectal cancer (HNPCC) and in a variety of sporadic cancers. Replication slippage of repetitive sequences introduce mispairing of nucleotides. These errors are removed by MMR and defects in MMR increase mutation rates leading to the development of tumors. The MMR system consists of four stages: 1) mismatch 


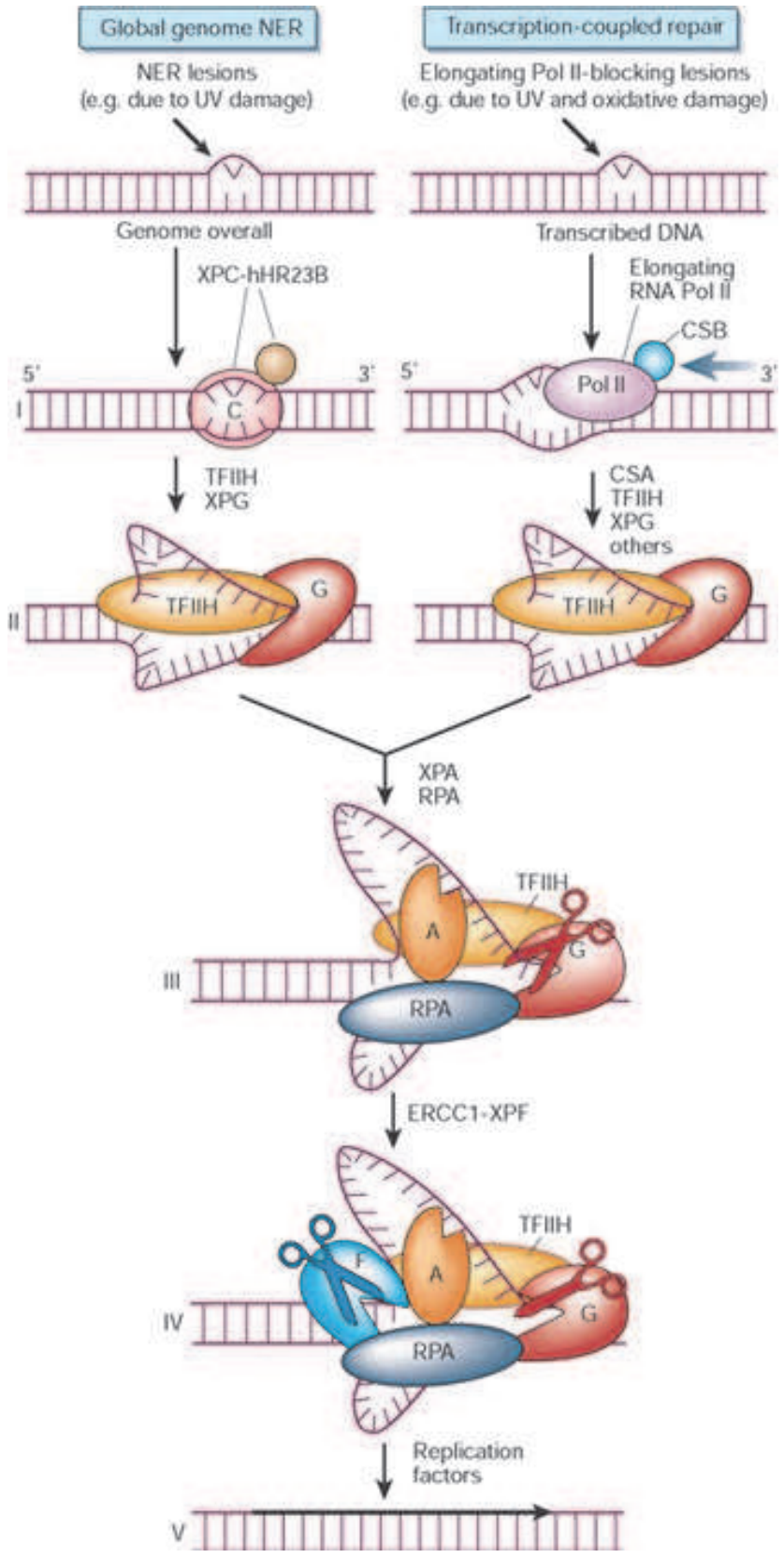

Fig. 3. Two NER subpathways exist with partly distinct substrate specificity: global genome NER (GG-NER) surveys the entire genome for distorting injury, and transcription-coupled repair (TCR) focuses on damage that blocks elongating RNA polymerases. Figure taken from Hoeijmakers ${ }^{30}$ 
recognition, 2) recruitment of MMR factors, 3) identification and degradation of the mismatch containing strand, and 4) synthesis of the new strand (Figure 4). HNPCC is an inherited disease caused, in $60 \%$ of cases, by germline mutations in $h M L H 1$ and $h M S H 2$ genes. Defects in $h M S H 6$ cause late-onset HNPCC. Mice that are completely MMR deficient show a normal development ${ }^{28}$ but are cancer-prone. Homologous recombination (HR) has been proposed to play a role in repairing double-strand breaks as a result of cisplatininduced crosslinks. ${ }^{23} \mathrm{HR}$ is not discussed in this chapter but different DNA repair systems are discussed in an excellent review by Hoeijmakers..$^{30}$

\begin{tabular}{ccc}
\hline Gene name & other name & Function \\
\hline ERCC1 & ERCC1 & Forms complex with XPF for 5'-incision \\
XPA & XPA & Verifies DNA damage \\
XPB & ERCC3 & $3^{\prime}->5^{\prime}$ helicase \\
XPC & XPC & Sensor for DNA damage \\
XPD & ERCC2 & $5^{\prime}->3^{\prime}$ helicase \\
XPE & DDB2 & Damage specific binding \\
XPF & ERCC4 & Forms complex with ERCC1 for $5^{\prime}$-incision \\
XPG & ERCC5 & $3^{\prime}$-incision \\
CSA & ERCC8 & Forms complex with CSB in TCR \\
CSB & ERCC6 & Binds stalled polymerase II in TCR \\
\hline
\end{tabular}

Table 1. Key enzymes in NER

\section{Cellular response to platinum-DNA adducts}

As described above, cells possess several DNA repair mechanisms for removing Pt-DNA adducts. The tumor specificity of oxaliplatin and cisplatin is not fully understood. Although both drugs cause DNA damage, the DNA repair mechanism of the host cell responds differently to these drugs. For example, damage caused by oxaliplatin is restored by the nucleotide excision repair mechanism, whereas the mismatch repair mechanism is also active to restore damage caused by cisplatin. 10,54 So, what is the underlying mechanism that makes certain tumors more sensitive to cisplatin than to oxaliplatin? Resistance to platinum anticancer agents can result from decreased accumulation, increased inactivation by glutathione, or an increased ability of cells to tolerate Pt-DNA adducts. ${ }^{1}$ The ability of cells to repair platinum-induced DNA lesions is known to be an important factor in cisplatin cytotoxicity. ${ }^{13}$

Interestingly, oxaliplatin induced DNA damage is as effectively repaired as cisplatininduced damage, as shown in plasmid reactivation experiments. ${ }^{71}$ The nucleotide excision repair has an extremely broad specificity, therefore it is not surprising that NER does not discriminate between oxaliplatin and cisplatin DNA adducts. ${ }^{66}$ The MMR system, however, is a crucial element in the repair of cisplatin-induced damage as this system does not appear 


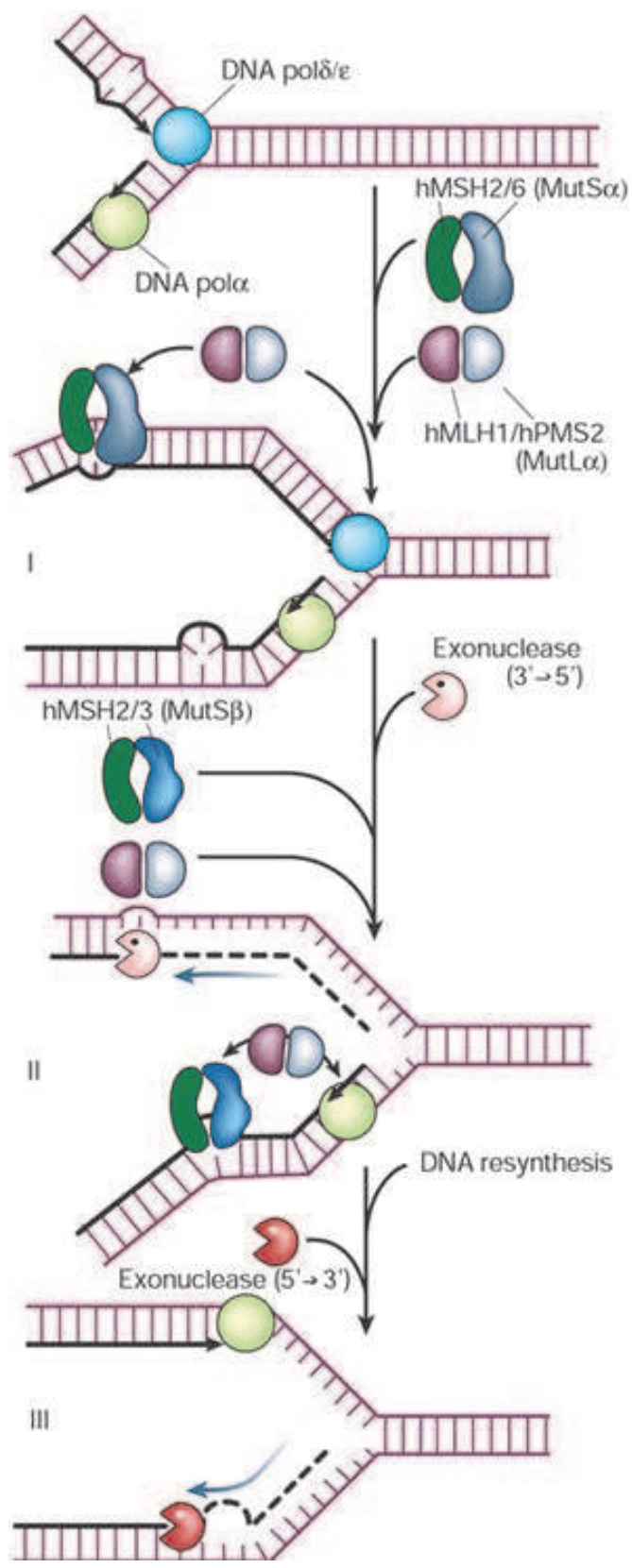

Fig. 4. Four principal steps in MMR can be delineated: (1) mismatch recognition; (2) recruitment of additional MMR factors; (3) search for a signal that identifies the wrong (newly synthesized) strand, followed by degradation past the mismatch; and (4) resynthesis of the excised tract. Figure taken from Hoeijmakers ${ }^{30}$ 
to recognize diaminocyclohexane-containing platinum ${ }^{64}$ DNA-adducts such as those caused by oxaliplatin. Although cells definitely respond differently to oxaliplatin and cisplatin, the mechanism behind that has still to be elucidated. Many studies that investigate the role of DNA repair mechanism in repairing DNA crosslinks, use cisplatin or mitomycin $\mathrm{C}$ as a model to induce such crosslinks. ${ }^{57}$ For instance the human ovarian cell line A2780 is sensitive to cisplatin but resistant to oxaliplatin. ${ }^{48}$ In this study it was shown that ERCC1 (a key enzyme in NER) mRNA is upregulated after exposure to cisplatin. Whether ERCC1 mRNA levels are upregulated after exposure to oxaliplatin, is not known.

\section{The role of DNA repair enzymes in platinum resistance}

There is growing evidence that activity of DNA repair enzymes contributes to the interindividual differences in the anti-tumor effect of platinum drugs. Activity of DNA repair system is affected by functional SNPs in key enzymes, but also expression levels of such enzymes might differ between individuals. High levels of ERCC1 mRNA are associated with worse outcome in patients with bladder cancer treated with oxaliplatin. ${ }^{3}$ An SNP in exon 4 of ERCC1 (rs11615) was associated with better survival in non-small cell lung carcinoma treated with cisplatin, ${ }^{34}$ as was in colorectal cancer patients treated with oxaliplatin. ${ }^{62,81}$ The ERCC2 gene (XPD) is located at the same chromosome as ERCC1 and multiple non-synonomous SNPs in ERCC2 have been found associated with diminished DNA repair capacity. ${ }^{74}$ Since rs11615 is a silent SNP (not causing amino acid change) the association with diminished DNA repair capacity is suggested to be due to low ERCC1 expression caused by a linked SNP (rs3212986) in its 3'NTR region. ${ }^{34}$ In vitro studies to test this hypothesis have not been performed. Interestingly, another gene in a reverse orientation, overlaps with ERCC1 3'NTR, and a role for this gene in DNA repair has been suggested. ${ }^{69}$ This gene was identified in 1999 as a CD3e binding protein in T-cells and was therefore named CAST (CD3 $\varepsilon$-associated signal transducer). ${ }^{86}$ Later, this gene was identified as a subunit of RNA Polymerase I. ${ }^{60}$ While the exact function of this Pol I-specific subunit is unknown, in mammalian cells the interaction with the activator of Pol I transcription, UBF, suggests a role for this subunit in facilitating the transition from transcription initiation to elongation at promoter escape. ${ }^{59}$ In another model it has been proposed that conformational changes in the Pol I enzyme complex through CAST convert the Pol I into a processive enzyme complex. ${ }^{60}$ Since the $3^{\prime}$ NTR of ERCC1 overlaps with CAST open reading frame, rs3212986 causes an amino acid change in CAST in a putative nuclear localization signal. It is likely that this SNP affects CAST function instead of ERCC1 expression. The hypothesis that CAST function is related with DNA repair is strengthened by its chromosomal location, between ERCC1 and ERCC2 (Figure 5).

An effect of platinum-based drugs on RNA polymerase I transcription is not without precedent. Cisplatin-induced platinum adducts interact with proteins that contain highmobility-group (HMG) domains, such as UBF, an activator of Pol I transcription. UBF was able to bind cisplatin-modified DNA more avidly than unmodified DNA ${ }^{12}$ and caused a redistribution of UBF in the nucleolus and a block of rRNA synthesis in human cells. ${ }^{37}$ Furthermore, UBF expression could increase the cell sensitivity to the chemotherapeutic reagent cis-diaminedichloroplatinum, ${ }^{32}$ perhaps by inhibiting repair of the DNA adducts. In addition, SNPs in CAST gene are associated with adult onset glioma ${ }^{11,85}$ and treatment outcome in multiple myeloma patients undergoing bone marrow transplantation. ${ }^{79}$ In view of the model where Pol I transcription of the rRNA genes is a sensor for DNA damage and 
of the intricate association of CAST with Pol I, rs3212986 could result in a CAST-Pol I complex with a decreased capacity to elicit a DNA damage response. In those cells that carry this particular SNP, damage is therefore not efficiently repaired and this might result in increased cytotoxicity to platinum drugs, impairement of tumour growth and hence an increased patient survival.

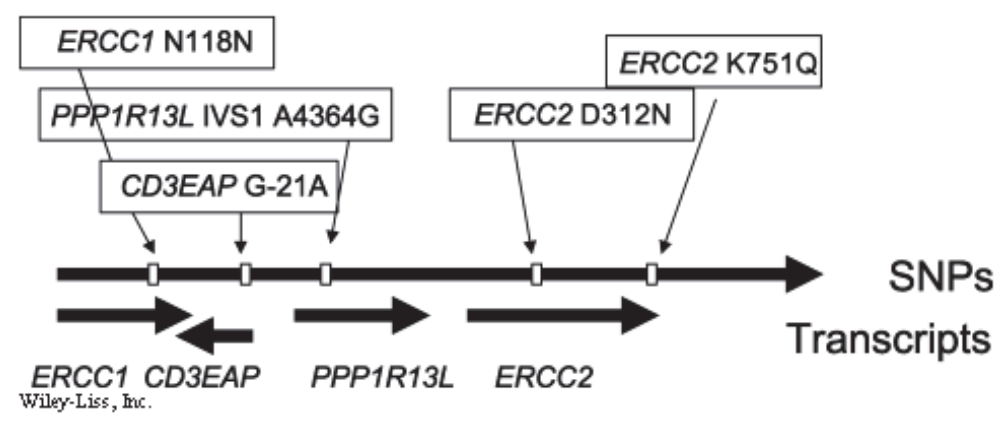

Fig. 5. Graphical presentation of the studied SNPs on chromosome 19. The ERCC1 polymorphism is silent and does not result in an amino acid substitution. The CD3EAP polymorphism is $\mathrm{G}$ to $\mathrm{A}$ transversion in the $5^{r}$ untranslated region of the mRNA. The PPP1R13L polymorphism is in intron 1 of the PPP1R13L gene. The ERCC2 D312N polymorphism gives rise to the Asp to Asn amino acid substitution in position 312 of ERCC2. ERCC2 K751Q gives rise to the Lys to Gln substitution in position 751 in ERCC2. Figure taken from Vangsted et al ${ }^{79}$

\section{Pharmacogenetic research of DNA repair genes in practice}

Cisplatin pharmacogenetics have been studied in esophageal cancer patients where several SNPs in NER were investigated. Two SNPs in ERCC1 and the SNP in ERCC1 3'-NTR (or CAST as discussed above) were found associated with improved overall survival. ${ }^{6}$ In testicular cancer cells, cisplatin sensitivity has been associated with low expression of ERCC1, however no SNPs were investigated in this study. ${ }^{77}$ Low expression of ERCC1 was also associated with oxaliplatin cytotoxicity in colorectal cancer cell lines when cetuximab (monoclonal antibody raised against EGFR) was co-administered. ${ }^{2}$ Platinum resistant ovarian cancer patients receive carboplatin together with gemcitabine ${ }^{49}$ that appeared to inhibit carboplatin induced interstrand crosslink repair. ${ }^{4,47}$ The role of ERCC1 in platinum treatment of non- small cell lung cancer with emphasis on carboplatin, has been reviewed by Vilmar and Sorensen. ${ }^{82}$ Recently, an explorative study has been performed to identify novel candidate genes related to oxaliplatin efficacy and toxicity in colorectal cancer patients, using a DNA repair array. ${ }^{43}$ Only ERCC5 (another factor in NER) and ATM (general responder to DNA damage) were found associated with clinical response. Discrepancies in association with SNPs in other DNA repair enzymes, present on the array, are discussed in this paper.

\section{Summary}

Since the entire human genome has been sequenced and 3,000,000 (1 in 1000 nucelotides) SNPs have been identified, more and more research is being performed to test effects of 
specific SNPs. Pharmacogenetic research is particularly focused on SNPs with a high allele frequency and an altered response to drugs. Many association studies have been performed and SNPs in genes encoding for drug transport, uptake, metabolism, detoxification and DNA repair, are found to be related to drug response. SNPs in coding regions may alter gene function, however, associated SNPs are not causal per se but may be linked to another, yet unidentified, linked SNP. The ultimate goal of pharmacogenetic research is to predict an individuals' response to drug therapy and subsequently adapt the therapeutic strategy. Peripheral blood can be taken to isolate chromosomal DNA and to genotype for specific SNPs, although tumor DNA might contain more mutations. In addition, expression levels of key enzymes may differ in tumor cells compared to normal cells. An approach to measure mRNA expression or to genotype tumor DNA could be the isolation of circulating tumor cells from peripheral blood. Whether this is feasible and cost effective for diagnostic healthcare should be investigated. In conclusion, more research is needed before any of the associated SNPs in DNA repair enzymes could be used to predict an individual response to a specific platinum-drug.

\section{References}

[1] Arnould, S., I. Hennebelle, P. Canal, R. Bugat, and S. Guichard. 2003. Cellular determinants of oxaliplatin sensitivity in colon cancer cell lines. Eur.J.Cancer 39:112-119.

[2] Balin-Gauthier, D., J. P. Delord, M. J. Pillaire, P. Rochaix, J. S. Hoffman, R. Bugat, C. Cazaux, P. Canal, and B. C. Allal. 2008. Cetuximab potentiates oxaliplatin cytotoxic effect through a defect in NER and DNA replication initiation. Br.J.Cancer. 98:120128.

[3] Bellmunt, J., L. Paz-Ares, M. Cuello, F. L. Cecere, S. Albiol, V. Guillem, E. Gallardo, J. Carles, P. Mendez, J. J. de la Cruz, M. Taron, R. Rosell, and J. Baselga. 2007. Gene expression of ERCC1 as a novel prognostic marker in advanced bladder cancer patients receiving cisplatin-based chemotherapy. Ann.Oncol. 18:522-528.

[4] Bergman, A. M., v. H. Ruiz, V, G. Veerman, C. M. Kuiper, and G. J. Peters. 1996. Synergistic interaction between cisplatin and gemcitabine in vitro. Clin.Cancer Res. 2:521-530.

[5] Borst, P., R. Evers, M. Kool, and J. Wijnholds. 2000. A family of drug transporters: the multidrug resistance-associated proteins. J.Natl.Cancer Inst. 92:1295-1302.

[6] Bradbury, P. A., M. H. Kulke, R. S. Heist, W. Zhou, C. Ma, W. Xu, A. L. Marshall, R. Zhai, S. M. Hooshmand, K. Asomaning, L. Su, F. A. Shepherd, T. J. Lynch, J. C. Wain, D. C. Christiani, and G. Liu. 2009. Cisplatin pharmacogenetics, DNA repair polymorphisms, and esophageal cancer outcomes. Pharmacogenet.Genomics. 19:613-625.

[7] Brinker, R. R. and P. Ranganathan. 2010. Methotrexate pharmacogenetics in rheumatoid arthritis. Clin.Exp.Rheumatol. 28:S33-S39.

[8] bu-Surrah, A. S. 2007. Development and current status of unconventional platinum anticancer complexes. Mini.Rev.Med.Chem. 7:203-211.

[9] Cepeda, V., M. A. Fuertes, J. Castilla, C. Alonso, C. Quevedo, and J. M. Perez. 2007. Biochemical mechanisms of cisplatin cytotoxicity. Anticancer Agents Med.Chem. 7:3-18. 
[10] Chaney, S. G., S. L. Campbell, E. Bassett, and Y. Wu. 2005. Recognition and processing of cisplatin- and oxaliplatin-DNA adducts. Crit Rev.Oncol.Hematol. 53:3-11.

[11] Chen, P., J. Wiencke, K. Aldape, A. Kesler-Diaz, R. Miike, K. Kelsey, M. Lee, J. Liu, and M. Wrensch. 2000. Association of an ERCC1 polymorphism with adult-onset glioma. Cancer Epidemiol.Biomarkers Prev. 9:843-847.

[12] Codony-Servat, J., R. Gimeno, C. Gelpi, J. L. Rodriguez-Sanchez, and C. Juarez. 1996. The two isoforms of the $90-\mathrm{kDalton}$ nucleolus organizer region autoantigen (upstream binding factor) bind with different avidity to DNA modified by the antitumor drug cisplatin. Biochem.Pharmacol. 51:1131-1136.

[13] Damia, G., G. Guidi, and M. D'Incalci. 1998. Expression of genes involved in nucleotide excision repair and sensitivity to cisplatin and melphalan in human cancer cell lines. Eur.J.Cancer 34:1783-1788.

[14] de, B. J. and J. H. Hoeijmakers. 1999. Cancer from the outside, aging from the inside: mouse models to study the consequences of defective nucleotide excision repair. Biochimie. 81:127-137.

[15] de, L. J. 2006. AmpliChip CYP450 test: personalized medicine has arrived in psychiatry. Expert.Rev.Mol.Diagn. 6:277-286.

[16] Deeken, J. 2009. The Affymetrix DMET platform and pharmacogenetics in drug development. Curr.Opin.Mol.Ther. 11:260-268.

[17] Desoize, B. and C. Madoulet. 2002. Particular aspects of platinum compounds used at present in cancer treatment. Crit Rev.Oncol.Hematol. 42:317-325.

[18] Di Francesco, A. M., A. Ruggiero, and R. Riccardi. 2002. Cellular and molecular aspects of drugs of the future: oxaliplatin. Cell Mol.Life Sci. 59:1914-1927.

[19] Distefano, J. K. and R. M. Watanabe. 2010. Pharmacogenetics of Anti-Diabetes Drugs. Pharmaceuticals.(Basel). 3:2610-2646.

[20] Eastman, A. 1987. The formation, isolation and characterization of DNA adducts produced by anticancer platinum complexes. Pharmacol.Ther. 34:155-166.

[21] Evans, W. E. and J. A. Johnson. 2001. Pharmacogenomics: the inherited basis for interindividual differences in drug response. Annu.Rev.Genomics Hum.Genet. 2:939.:9-39.

[22] Evans, W. E. and M. V. Relling. 1999. Pharmacogenomics: translating functional genomics into rational therapeutics. Science. 286:487-491.

[23] Frankenberg-Schwager, M., D. Kirchermeier, G. Greif, K. Baer, M. Becker, and D. Frankenberg. 2005. Cisplatin-mediated DNA double-strand breaks in replicating but not in quiescent cells of the yeast Saccharomyces cerevisiae. Toxicology. 212:175-184.

[24] Han, X. M. and H. H. Zhou. 2000. Polymorphism of CYP450 and cancer susceptibility. Acta Pharmacol.Sin. 21:673-679.

[25] Hanahan, D. and R. A. Weinberg. 2000. The hallmarks of cancer. Cell. 100:57-70.

[26] Helbekkmo, N., S. H. Sundstrom, U. Aasebo, P. F. Brunsvig, P. C. von, H. H. Hjelde, O. K. Garpestad, A. Bailey, and R. M. Bremnes. 2007. Vinorelbine/carboplatin vs gemcitabine/carboplatin in advanced NSCLC shows similar efficacy, but different impact of toxicity. Br.J.Cancer. 97:283-289.

[27] Hess, P. and D. Cooper. 1999. Impact of pharmacogenomics on the clinical laboratory. Mol.Diagn. 4:289-298. 
[28] Heyer, J., K. Yang, M. Lipkin, W. Edelmann, and R. Kucherlapati. 1999. Mouse models for colorectal cancer. Oncogene. \%20;18:5325-5333.

[29] Higby, D. J., H. J. Wallace, Jr., D. J. Albert, and J. F. Holland. 1974. Diaminodichloroplatinum: a phase I study showing responses in testicular and other tumors. Cancer. 33:1219-5.

[30] Hoeijmakers, J. H. 2001. Genome maintenance mechanisms for preventing cancer. Nature 411:366-374.

[31] Horwich, A., J. Shipley, and R. Huddart. 2006. Testicular germ-cell cancer. Lancet. 367:754-765.

[32] Huang, R., T. Wu, L. Xu, A. Liu, Y. Ji, and G. Hu. 2002. Upstream binding factor upregulated in hepatocellular carcinoma is related to the survival and cisplatinsensitivity of cancer cells. FASEB J. 16:293-301.

[33] Ingelman-Sundberg, M. and S. C. Sim. 2010. Pharmacogenetic biomarkers as tools for improved drug therapy; emphasis on the cytochrome P450 system. Biochem.Biophys.Res.Commun. 396:90-94.

[34] Isla, D., C. Sarries, R. Rosell, G. Alonso, M. Domine, M. Taron, G. Lopez-Vivanco, C. Camps, M. Botia, L. Nunez, M. Sanchez-Ronco, J. J. Sanchez, M. Lopez-Brea, I. Barneto, A. Paredes, B. Medina, A. Artal, and P. Lianes. 2004. Single nucleotide polymorphisms and outcome in docetaxel-cisplatin-treated advanced non-smallcell lung cancer. Ann.Oncol. 15:1194-1203.

[35] Jennerwein, M. M., A. Eastman, and A. Khokhar. 1989. Characterization of adducts produced in DNA by isomeric 1,2-diaminocyclohexaneplatinum(II) complexes. Chem.Biol.Interact. 70:39-49.

[36] Jiricny, J. 1998. Replication errors: cha(lle)nging the genome. EMBO J. 17:6427-6436.

[37] Jordan, P. and M. Carmo-Fonseca. 1998. Cisplatin inhibits synthesis of ribosomal RNA in vivo. Nucleic Acids Res. 26:2831-2836.

[38] Kalow, W. 1965. Contribution of hereditary factors to the response to drugs. Fed.Proc. 24:1259-1265.

[39] Kim, E. S., F. R. Khuri, and R. S. Herbst. 2001. Epidermal growth factor receptor biology (IMC-C225). Curr.Opin.Oncol. 13:506-513.

[40] Kleyn, P. W. and E. S. Vesell. 1998. Genetic variation as a guide to drug development. Science. 281:1820-1821.

[41] Komoto, C., T. Nakamura, T. Sakaeda, D. L. Kroetz, T. Yamada, H. Omatsu, T. Koyama, N. Okamura, I. Miki, T. Tamura, N. Aoyama, M. Kasuga, and K. Okumura. 2006. MDR1 haplotype frequencies in Japanese and Caucasian, and in Japanese patients with colorectal cancer and esophageal cancer. Drug Metab Pharmacokinet. 21:126-132.

[42] Kooloos, W. M., T. W. Huizinga, H. J. Guchelaar, and J. A. Wessels. 2010. Pharmacogenetics in treatment of rheumatoid arthritis. Curr.Pharm.Des. 16:164175.

[43] Kweekel, D. M., N. F. Antonini, J. W. Nortier, C. J. Punt, H. Gelderblom, and H. J. Guchelaar. 2009. Explorative study to identify novel candidate genes related to oxaliplatin efficacy and toxicity using a DNA repair array. Br.J.Cancer. 101:357-362.

[44] Kweekel, D. M., H. Gelderblom, and H. J. Guchelaar. 2005. Pharmacology of oxaliplatin and the use of pharmacogenomics to individualize therapy. Cancer Treat.Rev. 31:90-105. 
[45] Lagerstedt, R. K., T. Liu, J. Vandrovcova, B. Halvarsson, M. Clendenning, T. Frebourg, N. Papadopoulos, K. W. Kinzler, B. Vogelstein, P. Peltomaki, R. D. Kolodner, M. Nilbert, and A. Lindblom. 2007. Lynch syndrome (hereditary nonpolyposis colorectal cancer) diagnostics. J.Natl.Cancer Inst. 99:291-299.

[46] Le, P. F., E. E. Kwoh, A. Avrutskaya, A. Gentil, S. A. Leadon, A. Sarasin, and P. K. Cooper. 2000. Transcription-coupled repair of 8-oxoguanine: requirement for XPG, TFIIH, and CSB and implications for Cockayne syndrome. Cell. 101:159-171.

[47] Ledermann, J. A., H. Gabra, G. C. Jayson, V. J. Spanswick, G. J. Rustin, M. Jitlal, L. E. James, and J. A. Hartley. 2010. Inhibition of carboplatin-induced DNA interstrand cross-link repair by gemcitabine in patients receiving these drugs for platinumresistant ovarian cancer. Clin.Cancer Res. 16:4899-4905.

[48] Li, Q., K. Gardner, L. Zhang, B. Tsang, F. Bostick-Bruton, and E. Reed. 1998. Cisplatin induction of ERCC-1 mRNA expression in A2780/CP70 human ovarian cancer cells. J.Biol.Chem. 273:23419-23425.

[49] Lund, B., O. P. Hansen, K. Theilade, M. Hansen, and J. P. Neijt. 1994. Phase II study of gemcitabine $\left(2^{\prime}, 2^{\prime}\right.$-difluorodeoxycytidine) in previously treated ovarian cancer patients. J.Natl.Cancer Inst. \%19;86:1530-1533.

[50] MacPhee, I. A. 2010. Use of pharmacogenetics to optimize immunosuppressive therapy. Ther.Drug Monit. 32:261-264.

[51] Malandrino, N. and R. J. Smith. 2011. Personalized medicine in diabetes. Clin.Chem. 57:231-240.

[52] Marsal, S. and A. Julia. 2010. Rheumatoid arthritis pharmacogenomics. Pharmacogenomics. 11:617-619.

[53] Marsh, S., H. McLeod, E. Dolan, S. J. Shukla, C. A. Rabik, L. Gong, T. HernandezBoussard, X. J. Lou, T. E. Klein, and R. B. Altman. 2009. Platinum pathway. Pharmacogenet.Genomics. 19:563-564.

[54] Martin, L. P., T. C. Hamilton, and R. J. Schilder. 2008. Platinum resistance: the role of DNA repair pathways. Clin.Cancer Res. 14:1291-1295.

[55] Misset, J. L., H. Bleiberg, W. Sutherland, M. Bekradda, and E. Cvitkovic. 2000. Oxaliplatin clinical activity: a review. Crit Rev.Oncol.Hematol. 35:75-93.

[56] Morrow, P. K. and E. S. Kim. 2005. New biological agents in the treatment of advanced non-small cell lung cancer. Semin.Respir.Crit Care Med. 26:323-332.

[57] Niedernhofer, L. J., G. A. Garinis, A. Raams, A. S. Lalai, A. R. Robinson, E. Appeldoorn, H. Odijk, R. Oostendorp, A. Ahmad, W. van Leeuwen, A. F. Theil, W. Vermeulen, G. T. van der Horst, P. Meinecke, W. J. Kleijer, J. Vijg, N. G. Jaspers, and J. H. Hoeijmakers. 2006. A new progeroid syndrome reveals that genotoxic stress suppresses the somatotroph axis. Nature 444:1038-1043.

[58] Page, J. D., I. Husain, A. Sancar, and S. G. Chaney. 1990. Effect of the diaminocyclohexane carrier ligand on platinum adduct formation, repair, and lethality. Biochemistry. 29:1016-1024.

[59] Panov, K. I., J. K. Friedrich, J. Russell, and J. C. Zomerdijk. 2006. UBF activates RNA polymerase I transcription by stimulating promoter escape. EMBO J. 25:3310-3322.

[60] Panov, K. I., T. B. Panova, O. Gadal, K. Nishiyama, T. Saito, J. Russell, and J. C. Zomerdijk. 2006. RNA polymerase I-specific subunit CAST/hPAF49 has a role in the activation of transcription by upstream binding factor. Mol.Cell Biol. 26:54365448 . 
[61] Papadopoulos, N. and A. Lindblom. 1997. Molecular basis of HNPCC: mutations of MMR genes. Hum.Mutat. 10:89-99.

[62] Pare, L., E. Marcuello, A. Altes, R. E. del, L. Sedano, J. Salazar, A. Cortes, A. Barnadas, and M. Baiget. 2008. Pharmacogenetic prediction of clinical outcome in advanced colorectal cancer patients receiving oxaliplatin/5-fluorouracil as first-line chemotherapy. Br.J.Cancer. 99:1050-1055.

[63] Pirker, R. and M. Filipits. 2010. Monoclonal antibodies against EGFR in non-small cell lung cancer. Crit Rev.Oncol.Hematol.

[64] Rabik, C. A. and M. E. Dolan. 2007. Molecular mechanisms of resistance and toxicity associated with platinating agents. Cancer Treat.Rev. 33:9-23.

[65] Raymond, E., S. Faivre, S. Chaney, J. Woynarowski, and E. Cvitkovic. 2002. Cellular and molecular pharmacology of oxaliplatin. Mol.Cancer Ther. 1:227-235.

[66] Reardon, J. T., A. Vaisman, S. G. Chaney, and A. Sancar. 1999. Efficient nucleotide excision repair of cisplatin, oxaliplatin, and Bis-aceto-ammine-dichlorocyclohexylamine-platinum(IV) (JM216) platinum intrastrand DNA diadducts. Cancer Res. 59:3968-3971.

[67] Roses, A. D. 2000. Pharmacogenetics and the practice of medicine. Nature. 405:857-865.

[68] Rusnak, J. M., R. M. Kisabeth, D. P. Herbert, and D. M. McNeil. 2001. Pharmacogenomics: a clinician's primer on emerging technologies for improved patient care. Mayo Clin.Proc. 76:299-309.

[69] Russell, J. and J. C. Zomerdijk. 2005. RNA-polymerase-I-directed rDNA transcription, life and works. Trends Biochem.Sci. 30:87-96.

[70] Sakaeda, T., T. Nakamura, M. Horinouchi, M. Kakumoto, N. Ohmoto, T. Sakai, Y. Morita, T. Tamura, N. Aoyama, M. Hirai, M. Kasuga, and K. Okumura. 2001. MDR1 genotype-related pharmacokinetics of digoxin after single oral administration in healthy Japanese subjects. Pharm.Res. 18:1400-1404.

[71] Scheeff, E. D., J. M. Briggs, and S. B. Howell. 1999. Molecular modeling of the intrastrand guanine-guanine DNA adducts produced by cisplatin and oxaliplatin. Mol.Pharmacol. 56:633-643.

[72] Seufferlein, T. and B. O. Boehm. 2002. The impact of pharmacogenomics on gastrointestinal cancer therapy. Pharmacogenomics. 3:625-633.

[73] Severino, G., C. Chillotti, M. E. Stochino, and Z. M. Del. 2003. Pharmacogenomics: state of the research and perspectives in clinical application. Neurol.Sci. 24 Suppl 2:S1468.:S146-S148.

[74] Spitz, M. R., X. Wu, Y. Wang, L. E. Wang, S. Shete, C. I. Amos, Z. Guo, L. Lei, H. Mohrenweiser, and Q. Wei. 2001. Modulation of nucleotide excision repair capacity by XPD polymorphisms in lung cancer patients. Cancer Res. 61:1354-1357.

[75] Tang, J. Y., B. J. Hwang, J. M. Ford, P. C. Hanawalt, and G. Chu. 2000. Xeroderma pigmentosum $\mathrm{p} 48$ gene enhances global genomic repair and suppresses UVinduced mutagenesis. Mol.Cell. 5:737-744.

[76] Tornaletti, S. and P. C. Hanawalt. 1999. Effect of DNA lesions on transcription elongation. Biochimie. 81:139-146.

[77] Usanova, S., A. Piee-Staffa, U. Sied, J. Thomale, A. Schneider, B. Kaina, and B. Koberle. 2010. Cisplatin sensitivity of testis tumour cells is due to deficiency in interstrandcrosslink repair and low ERCC1-XPF expression. Mol.Cancer. 9:248.:248. 
[78] van Glabbeke, M., J. Renard, H. M. Pinedo, F. Cavalli, J. Vermorken, C. Sessa, R. Abele, M. Clavel, and S. Monfardini. 1988. Iproplatin and carboplatin induced toxicities: overview of phase II clinical trial conducted by the EORTC Early Clinical Trials Cooperative Group (ECTG). Eur.J.Cancer Clin.Oncol. 24:255-262.

[79] Vangsted, A., P. Gimsing, T. W. Klausen, B. A. Nexo, H. Wallin, P. Andersen, P. Hokland, S. T. Lillevang, and U. Vogel. 2007. Polymorphisms in the genes ERCC2, XRCC3 and CD3EAP influence treatment outcome in multiple myeloma patients undergoing autologous bone marrow transplantation. Int.J.Cancer 120:1036-1045.

[80] Vermeulen, W., S. Rademakers, N. G. Jaspers, E. Appeldoorn, A. Raams, B. Klein, W. J. Kleijer, L. K. Hansen, and J. H. Hoeijmakers. 2001. A temperature-sensitive disorder in basal transcription and DNA repair in humans. Nat.Genet. 27:299-303.

[81] Viguier, J., V. Boige, C. Miquel, M. Pocard, B. Giraudeau, J. C. Sabourin, M. Ducreux, A. Sarasin, and F. Praz. 2005. ERCC1 codon 118 polymorphism is a predictive factor for the tumor response to oxaliplatin/5-fluorouracil combination chemotherapy in patients with advanced colorectal cancer. Clin.Cancer Res. 11:6212-6217.

[82] Vilmar, A. and J. B. Sorensen. 2009. Excision repair cross-complementation group 1 (ERCC1) in platinum-based treatment of non-small cell lung cancer with special emphasis on carboplatin: a review of current literature. Lung Cancer. 64:131-139.

[83] Wang, D. and S. J. Lippard. 2005. Cellular processing of platinum anticancer drugs. Nat.Rev.Drug Discov. 4:307-320.

[84] Ware, N. and I. A. MacPhee. 2010. Current progress in pharmacogenetics and individualized immunosuppressive drug dosing in organ transplantation. Curr.Opin.Mol.Ther. 12:270-283.

[85] Wrensch, M., K. T. Kelsey, M. Liu, R. Miike, M. Moghadassi, J. D. Sison, K. Aldape, A. McMillan, J. Wiemels, and J. K. Wiencke. 2005. ERCC1 and ERCC2 polymorphisms and adult glioma. Neuro.-oncol. 7:495-507.

[86] Yamazaki, T., Y. Hamano, H. Tashiro, K. Itoh, H. Nakano, S. Miyatake, and T. Saito. 1999. CAST, a novel CD3epsilon-binding protein transducing activation signal for interleukin-2 production in T cells. J.Biol.Chem. 274:18173-18180. 


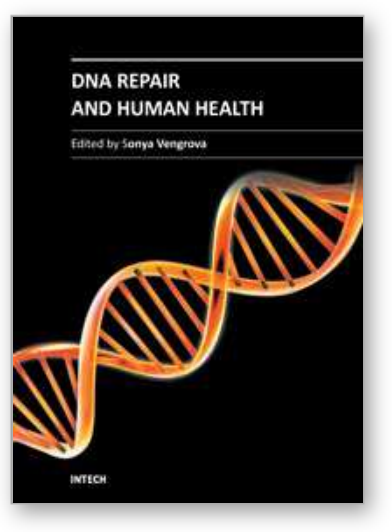

\author{
DNA Repair and Human Health \\ Edited by Dr. Sonya Vengrova
}

ISBN 978-953-307-612-6

Hard cover, 792 pages

Publisher InTech

Published online 26, October, 2011

Published in print edition October, 2011

Over the past decades, great advances have been made in understanding the cellular DNA repair pathways. At the same time, a wealth of descriptive knowledge of human diseases has been accumulated. Now, the basic research of the mechanisms of DNA repair is merging with clinical research, placing the action of the DNA repair pathways in the context of the whole organism. Such integrative approach enables understanding of the disease mechanisms and is invaluable in improving diagnostics and prevention, as well as designing better therapies. This book highlights the central role of DNA repair in human health and well-being. The reviews presented here, contain detailed descriptions of DNA repair pathways, as well as analysis of a large body of evidence addressing links between DNA damage repair and human health. They will be of interest to a broad audience, from molecular biologists working on DNA repair in any model system, to medical researchers.

\title{
How to reference
}

In order to correctly reference this scholarly work, feel free to copy and paste the following:

Tahar van der Straaten, Leon Mullenders and Henk-Jan Guchelaar (2011). Pharmacogenetics of Cancer and DNA Repair Enzymes, DNA Repair and Human Health, Dr. Sonya Vengrova (Ed.), ISBN: 978-953-307-612-6, InTech, Available from: http://www.intechopen.com/books/dna-repair-and-human-health/pharmacogenetics-ofcancer-and-dna-repair-enzymes

\section{INTECH}

open science | open minds

\author{
InTech Europe \\ University Campus STeP Ri \\ Slavka Krautzeka 83/A \\ 51000 Rijeka, Croatia \\ Phone: +385 (51) 770447 \\ Fax: +385 (51) 686166 \\ www.intechopen.com
}

\author{
InTech China \\ Unit 405, Office Block, Hotel Equatorial Shanghai \\ No.65, Yan An Road (West), Shanghai, 200040, China \\ 中国上海市延安西路65号上海国际贵都大饭店办公楼 405 单元 \\ Phone: +86-21-62489820 \\ Fax: $+86-21-62489821$
}


(C) 2011 The Author(s). Licensee IntechOpen. This is an open access article distributed under the terms of the Creative Commons Attribution 3.0 License, which permits unrestricted use, distribution, and reproduction in any medium, provided the original work is properly cited. 